Acta Poetica 31-2

JULIO-DICIEMBRE

$2010(247-264)$

\title{
Inquietud y alerta: experiencia moderna
}

\author{
José Francisco Barrón Tovar
}

Se trata de describir el campo problemático al que responde el ejercicio de pensamiento levinasiano. Los conceptos de experiencia de la heteronomía y de la alteridad deben ponerse en relación con otros ejercicios críticos del ámbito de lo humano abierto por la modernidad. Habría, pues, toda una lectura política por hacer de la relación de los esfuerzos especulativos levinasianos con los de aquellos que critican las experiencias modernas de lo humano.

Palabras ClaVE: experiencia heterónoma, libertad, inquietud, sensibilidad moderna.

This article intends to describe the problematic field, giving rise to Levinasian thought. The concepts of experienced heteronomy and otherness should be put in relation to other criticisms directed to the modernity-driven human sphere. Thus, we are still due with a comprehensive, political reading of the relationship between Levinasian speculative efforts and the works of other thinkers criticizing the modern human experience.

KeY wORDs: Heteronomous experience, liberty, uneasiness, modern sensibility.

Fecha de recepción: 1 de agosto de 2009.

Fecha de aceptación: 12 de abril de 2010. 

Acta Poetica 31-2

JULIO-DICIEMBRE

$2010(247-264)$

\author{
José Francisco Barrón Tovar \\ Facultad de Filosofía y Letras \\ Universidad Nacional Autónoma de México
}

\title{
Inquietud y alerta: experiencia moderna
}

\begin{abstract}
Que pueda crearse un alma de esclavo [...] es [...] la más desgarradora experiencia del hombre moderno.

Emmanuel Levinas, "Libertad y Mandamiento"

El prisionero no puede liberarse solo de su encierro. Tratado Berajot del Talmud Babilónico ${ }^{1}$
\end{abstract}

Poder convertirse en un lector de filosofía. ¿Cómo llegar a serlo? Leer filosofía. Y después de todo: ¿qué significa leer? Y luego, ¿qué significa leer filosofía? ¿Cómo se hace eso? ¿Qué hay para leer cuando se cree leer algo que aún consentimos en llamar filosofía? Gilles Deleuze escribe en una conferencia llamada "El acto de creación":

la filosofía no está hecha para reflexionar sobre cualquier cosa. No está hecha para reflexionar sobre otra cosa. Quiero decir que tratando a la filosofía como una potencia de reflexionar sobre, se cree darle mucho pero de hecho se le retira todo. Ya

${ }^{1}$ El texto es citado en Emmanuel Levinas, "El sufrimiento inútil", en Entre nosotros, 118 , nota 3 . 
que nadie tiene necesidad de la filosofía para reflexionar. [...] Si la filosofía debiera reflexionar sobre algo, no tendría razón de existir. Si la filosofía existe es porque ella tiene su propio contenido. Si nos preguntamos: ¿cuál es el contenido de la filosofía? Es muy simple. Es que la filosofía es una disciplina tan creadora, tan inventiva como cualquier otra. La filosofía es una disciplina que consiste en crear o en inventar conceptos. Y los conceptos no existen en absoluto en una especie de cielo en el que esperarían a que un filósofo los concibiera. A los conceptos es preciso fabricarlos ${ }^{2}$ (Deleuze, "L'acte de création").

"Inventar conceptos". La afirmación resulta problemática. Complica ese ejercicio de lo que podría llamarse lectura de la filosofía. Si la filosofía inventa conceptos, entonces de qué manera se ejercita la lectura de tales invenciones filosóficas. Si la filosofía inventa conceptos, habría que inventar filosóficas maneras de leer invenciones filosóficas. Habría que inventar una manera inventiva de leer, y también filosofía. Una manera inventiva y, por ello quizás, más justa. Y es que solo una invención responde por otra invención.

Deleuze, justo e inventivo lector de filosofía, escribe: "Cuando escribo sobre un autor, mi ideal sería no escribir nada que pudiera entristecerlo, o, en caso de que haya muerto, nada que pueda hacerle llorar en su tumba [...]. [Trataría de] devolver al autor un poco de la alegría, de la fuerza, de la vida amorosa y política que él ha sabido dar, inventar" (Deleuze y Parnet, Diálogos, 133). Con el pensamiento de Lévinas habría que acometer tal lectura filosófica. ¿Acaso no es esto lo que más desea un filósofo? Que se le lea “bien”, “justamente”. Más, ¿cómo ingeniárnoslas para poner contento a este filósofo muerto? ¿Para no entristecerlo, alegrarlo, provocarle esa sonrisa un poco perversa, un poco tierna, que tienen los filósofos? Y solo se me ocurre

${ }^{2}$ A partir de ahora toda traducción al español de un texto en francés será mía, a menos que se consigne otra cosa. 
una manera algo frágil y afanosa: con mucho cuidado y viva atención descubrir la manera en que fue fabricado y la manera de operar de uno de sus conceptos. Tan solo se me ocurre un concepto —al menos uno-: el de "experiencia heterónoma" (Levinas, La huella del otro, 53). Y quizás así, al hacer un uso político del concepto de experiencia heterónoma para repensarnos a nosotros mismos, Levinas se ría un poquito.

Cuando Levinas vuelve a echar a andar la constelación problemática de la experiencia moderna, lo hace después de que muchos pensadores habían diagnosticado ya, que varias cuestiones urgentes se jugaban en ella. ${ }^{3}$ Marx en los Manuscritos económico-filosóficos, ${ }^{4}$ Nietzsche en las Intempestivas ${ }^{5}$ y Benjamin en sus textos sobre la experiencia, ${ }^{6}$ habían atacado los

${ }^{3}$ Nuestro cometido aquí es el mismo que el de Franco cuando trata el concepto de rostro en Levinas: "C'est qu'il fallait montrer, contre certaines tendances, que le visage chez Lévinas n'est pas du pur révélé, transmission ou kabbale. Il vient en énième lieu, rassembler ou hériter ce qui est deja pensé avant lui" ["Lo que sería preciso mostrar, contra ciertas tendencias, es que el rostro en Lévinas no es puramente revelado, transmisión o cábala. Viene al final a congregar o heredar lo que se pensó antes de él"] ("Sur faces. Positions", 54).

${ }^{4}$ Cfr. Marx, Manuscritos. Sobre todo las partes donde afirma en tono de Feuerbach que: "las sensaciones, pasiones, etc., del hombre son no sólo determinaciones antropológicas en sentido estricto, sino verdaderamente afirmaciones ontológicas del ser (naturaleza) [...]. Sólo mediante la industria desarrollada, esto es, por la mediación de la propiedad privada, se constituye la esencia ontológica de la pasión humana, tanto en su totalidad como en su humanidad" ("Tercer manuscrito", 176-177); y encontraba en la modernidad capitalista que "todas las pasiones y toda actividad deben, pues, disolverse en la avaricia" (160), y que la sensibilidad del individuo se había degradado hasta convertirse en puro "aturdimiento" y "barbarie" (162).

${ }^{5}$ Cfr. Nietzsche, I Intempestiva, y II Intempestiva, 76-83. En la II Intempesti$v a$ Nietzsche encontraba que "el moderno padece de una personalidad debilitada" (76), una "perpetua carencia de subjetividad" (82) que implica el ejercicio de una experiencia en el que una "excitabilidad del sentimiento" (87) y unas "indigencia y miseria interiores" (79) reducen todo acontecimiento a "medios de excitación" de la sensibilidad y que sumen al individuo a la impotentia.

${ }^{6}$ Cfr. Benjamin, "Experiencia y pobreza", 167-173. Allí escribe Benjamin: "Una pobreza de experiencia del todo nueva ha caído sobre el hombre al tiempo que ese enorme desarrollo de la técnica [...]: la pobreza de nuestra experiencia no solo pobre en experiencias privadas, sino en las de la humanidad en general. Se trata de una especie de nueva barbarie" (169). 
modos de vida que el concepto de experiencia, implementado en la modernidad, permitía y alentaba. Algunas reflexiones sobre la filosofía del hitlerismo (1934) es el texto donde Levinas vuelve a operar sobre la cuestión de la experiencia. Aparece en una constelación problemática donde los conceptos de humanidad, libertad, pensamiento, verdad y cultura resuenan conjuntamente.

El ascenso del hitlerismo al poder no representa, según Levinas, tan solo una degradación del sistema político moderno, antes bien, "pone en cuestión los principios mismos de toda una civilización" (Algunas reflexiones, 7). Levinas es insistente en ello, pues "lo que está en juego" con la llegada del hitlerismo "es la humanidad misma del hombre" (21). En lugar de preguntarse por las condiciones históricas que permitieron su aparición, o de repudiar filosófica o religiosamente el que todo un pueblo civilizado haya volcado su destino hacia el hitlerismo, hará la pregunta sobre la experiencia singular del hitlerismo. Pues, lo que le impresiona en esa "puesta en juego" de la humanidad del hombre es la experiencia que la hace y se hace en ella posible. Lo que acometerá así Levinas es una "fenomenología" de la "sensibilidad moderna" (De la evasión, § 1, 78).

Fenomenología heterónoma. En su artículo de 1931, "Friburgo, Husserl y la fenomenología", Levinas interpretaba de este modo el método fenomenológico:

Su idea fundamental consiste [...] en afirmar y respetar la especificidad de la referencia al mundo que realiza el sentimiento. [La fenomenología] sostiene con convicción que hay relación, que los sentimientos como tales "quieren volverse algo" y que constituyen nuestra trascendencia con relación a nosotros mismos, nuestra inherencia al mundo (Levinas apud Abensour, Algunas reflexiones, 37$)$.

Por su parte, en Algunas reflexiones sobre la filosofía del hitlerismo definirá el sentimiento de la siguiente manera: "la 
actitud primera de un alma frente al conjunto de lo real y [frente] a su propio destino" (7). Los sentimientos no serán ya para Levinas los estados propios de una $\psi v \chi \eta$ (alma), sino "la relación del hombre con la exterioridad" ("Determinación filosófica", en Entre nosotros, 210), la pluralidad de maneras en que el hombre se relacionará con lo que le ocurre. Un sentimiento será "una manera de hacer experiencia, de pensar lo que hay" (Zourabichvili, "Événement", 38). Por ello, el asunto de la fenomenología levinasiana son las múltiples relaciones del hombre con lo que ocurre y la manera como el hombre responde ante ello (De la existencia, 132). ${ }^{7}$ De este modo, todas las descripciones fenomenológicas que Levinas hace del insomnio, de la vigilia, de la necesidad, del cansancio, de la náusea, etc., serán descripciones de las maneras humanas concretas de vivir lo que acontece. ${ }^{8}$

El hitlerismo es descrito por Levinas como el "despertar" de una experiencia que "implica una concepción del destino humano" (Algunas reflexiones, 8). Esta nueva concepción de lo humano destruye la anterior que privaba en el pensamiento y las formas de vida hasta ahora echadas a andar: concepción establecida sobre "el sentimiento de la libertad absoluta del hombre respecto del mundo y de las posibilidades que requieren su acción" (8). La experiencia del hombre libre es destruida, y en ese mismo momento otra despierta, la del moderno: "La esencia del hombre [...] está [...] — dice Levinas - en una especie de encadenamiento. Ser verdaderamente uno mismo [...] es [...] tomar conciencia del encadenamiento original ineluctable [...]; es, sobre todo, aceptar este encadenamiento" (17). Esta "nueva concepción del hombre" es la de un hombre encadenado a su propio ser del que "no se escapa" (16).

${ }^{7}$ En De la existencia al existente, Levinas afirmará que su "método consiste en abordar los estados como acontecimientos".

${ }^{8}$ Levinas afirma en la entrevista "Preguntas y respuestas": "es en la manera como existe, como vive [un sujeto que existe], en la que hay ética" (154). 
Después de Algunas reflexiones sobre la filosofía del hitlerismo Levinas ya no podrá abandonar la empresa de desmontar el funcionamiento de esa experiencia, a la vez que la de inventar un concepto diferente. De la evasión (1935) y De la existencia al existente (1947) serán las primeras tentativas de ambas empresas. El asunto de tales estudios es la experiencia de la "fatalidad del ser clavado a sí mismo" (Levinas, De la evasión, § 7, 112).

Los conceptos del Ser y del Hay son los dispositivos especulativos de los que Levinas echará mano para tratar de caracterizar esa experiencia. El Hay es la "experiencia misma del ser puro" $(\S 6,104)$. Asimismo, constituye la "presencia ineluctable" del acontecer de las cosas, la "condena a la realidad perpetua" (De la existencia, 84) de lo que acontece en este presente, la experiencia decisiva del "sin salida" (83) de este aquíy-ahora. Pero este Hay no solo es la experiencia del "sin salida", sino que acontece bajo la forma del "anonimato esencial" (78). Es el "acontecimiento impersonal, a-sustantivo" (85) de lo que ocurre. ${ }^{9}$ Es aquí donde se halla parte de lo que Levinas

${ }^{9}$ Es esto lo que reprochará siempre, injustamente o no, a Heidegger: "el Dasein es, a fin de cuentas, una estructura del ser en general que se atiene a su misión de ser, 'a su gesta de ser', a su acontecimiento de ser" (Levinas, "Filosofía", Entre nosotros, 137). Lo que molesta a Levinas del pensamiento de Heidegger son los efectos que sobre la figura de hombre implementa un pensamiento del "ser". La lectura de la figura del concepto heideggeriano del hombre de Levinas se basa en la lectura de Ser y tiempo, y en el concepto de Jemeinigkeit o "la condición de ser en-cada-casomío" que aparece allí. Levinas afirma en "Preguntas y respuestas": "Dasein significa que Dasein tiene que ser. ¡Pero esta 'obligación' de ser, esta manera de ser, es una exposición a ser tan directa que, por ello, se convierte en mía! [...]. La Jemeinigkeit es la medida extrema de la manera como el Dasein está sujeto a la esencia" (Levinas, "Preguntas y respuestas", 156-157). Para Levinas el hombre así concebido se encuentra encerrado en su ser.

Esta consecuencia deriva directamente, según Levinas, del pensamiento del das Ereignis que Heidegger trata de echar a andar. De acuerdo al Heidegger de "Tiempo y ser" (tomo XXII, 345-376), la apuesta de este pensamiento del acontecimiento de la verdad implica repensar la "relación del hombre con lo que hasta ahora se llamó 'Ser"”. En "Sólo un dios puede salvarnos todavía", Heidegger nos confiesa abiertamente que este cometido especulativo de re-pensar el concepto de hombre a partir 
buscaba: lo que encierra es el anonimato, lo que enclaustra es la impersonalidad, lo que aprisiona es el acontecimiento impersonal del Ser. La impersonalidad se confunde para Levinas con la irresponsabilidad. El hitlerismo condena al hombre a la experiencia del anonimato y de la irresponsabilidad.

Y es que para Levinas, si el acontecimiento del Ser es anónimo entonces entraña una radical "disolución del sujeto" (Entre nosotros, 84, nota 1), una elemental "experiencia de la des-

de sus relaciones con el Ser tiene que pasar por el desplazamiento hacia la pregunta por el concepto de acontecimiento de la verdad o das Ereignis. Allí mismo Heidegger afirma que este nuevo concepto de lo humano que trata de echar a andar debe ponerse a funcionar primeramente como la reformulación de la relación hombretécnica: "la tarea del Pensamiento es ayudar a [...] que el hombre en general llegue a lograr una relación con la Esencia de la técnica". Por ello, en "La pregunta por la técnica" afirma que la pregunta que guía su pensamiento es "cómo debemos entrar en relación con la esencia de la técnica". Para responder esa problemática Heidegger propone en "Tiempo y ser" un pensamiento del das Ereignis. Pero del acontecimiento de la verdad Heidegger afirma: "El acontecimiento-apropiador aconteceapropia [Das Ereignis ereignet]". Sólo hay acontecimiento de la verdad. Por ello para Heidegger el hombre debe concebirse como co-perteneciente de la aparición de la verdad. En "La pregunta por la técnica", escribe: "Cuando el hombre en el interior de la no-ocultación devela a su manera lo presente, entonces no hace más que responder al llamado de la no-ocultación, allí mismo donde la contradice". El concepto de hombre es el de un hombre co-perteneciente al develamiento de la verdad. Para Levinas esto debe entenderse como un encerramiento a lo que acontece. Más profundamente, lo que Levinas le impugna a Heidegger es su lectura del concepto

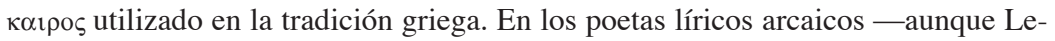
vinas se refiere en De la existencia al existente a los trágicos y a Epicuro, cfr. 119 y

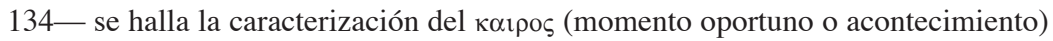
de este modo: "lo sucedido no se puede dar por no acontecido" (Simónides, fr. 247) o "la verdad se impone [ $\pi \alpha \gamma \kappa \rho \alpha \tau \varepsilon \varsigma]$ " (Simónides, fr. 224). Heidegger hace la lectura de tal concepto tradicional en la forma del llamado del ser o cura respecto al ser que en cada caso se es. En "La sentencia de Anaximandro", Heidegger relee en términos de "estado de necesidad que obliga" el $\chi \rho \varepsilon \omega v$ (obligación, necesidad, deber) con el que Anaximandro piensa el кхıрь (momento oportuno o acontecimiento). Así,

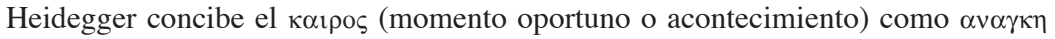
(necesidad, fuerza, coacción) o $\mu$ oip $\alpha$ (parte, porción, destino, lo convenido). Levinas nos asegura que esta lectura lleva a unas consecuencias desastrosas para el concepto de hombre. 


\title{
personalización" (91), una primordial "experiencia de la ser- vidumbre"10 (120). Así, lo que hay detrás de este problema, de
}

\begin{abstract}
${ }^{10}$ Con esta afirmación de la conformación de una experiencia-de-esclavo, con la producción de un "alma de esclavo", que el hitlerismo hace patente, Levinas realiza una genealogía de la inversión de los valores libertad / esclavitud. Por ejemplo, en Todo hombre bueno es libre, texto del siglo i a. de C. de Filón de Alejandría, se halla esta traducción: "el término esclavitud se aplica tanto a las almas como a los cuerpos; y los amos de los cuerpos son hombres, en tanto que los de las almas son los vicios y las pasiones. Y otro tanto cabe decir de la libertad, ya que existen la que lleva aparejada para los cuerpos la seguridad de no depender del superior poder de otros hombres; y la que permite a la inteligencia desenvolverse sin estar sujeta al dominio de las pasiones. Ninguna persona se aplica a investigar sobre la primera clase de libertad, pues las vicisitudes de los hombres son incontables y en muchas ocasiones muchas personas de muy elevada condición perdieron a causa de desgraciadas circunstancias la libertad heredada de sus mayores" (27-28).

Lo que llama la atención no es que Filón reproduzca una distinción platónica, en una época en la que se reformula la condición histórico-política del esclavo y la del libre y a la que muchos pensadores se abocaban — cfr. al menos Dión de Prusa, "Sobre la esclavitud" I, 75-83- La disputa en esa época era si se podía considerar legal-moral la esclavitud por compra de personas. En la Antigüedad clásica, la esclavitud tenía tres fuentes: 1) el nacimiento; 2) un juicio condenatorio por insolvencia; y 3) ser prisionero de guerra. El amo no tenía derecho de vida y muerte sobre el esclavo, de hecho, la relación amo-esclavo dependía del ejercicio de la virtud de quien mandaba. Ser hombre libre implicaba mandar justamente. La cuestión es que en el lapso entre la decadencia de Grecia y el surgimiento de Roma se hizo posible comprar esclavos. Lo sorprendente en este acercamiento de Filón a la cuestión es la afirmación de que nadie se aplicaría a investigar la libertad y la esclavitud del cuerpo. La afirmación está de acuerdo con los pocos textos que la Antigüedad nos heredó sobre la cuestión de la esclavitud — cfr.Vidal-Naquet, "Reflexiones"-. Este acercamiento político-moral de la cuestión depende de la cuestión sobre una $\beta$ tos

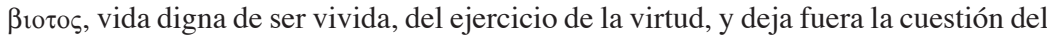
"cuerpo" porque parece que no es concebible para Filón que se produzcan las condiciones de existencia en las que los individuos no puedan ejercitarse en la libertad del "alma", en las que todos los individuos se hallen "esclavos de cuerpo". Filón no concibe un alma de esclavo.
\end{abstract}

De La Boétie en el texto Sobre la servidumbre voluntaria (1548) parece que comienza a hacer concebible tal cuestión, pero es hasta el siglo XIX, con el primer embate global del capitalismo y la tecnología, que los trabajos de los pensadores abundan sobre lo que ni Filón ni los filósofos antiguos se aplicaban. Para muestra $E l$ derecho a la pereza de Lafargue: " $¡ Y$ decir que los hijos de los héroes de la época de la Terreur se han dejado degradar por la religión del trabajo hasta el punto de aceptar, en 1848, como una conquista revolucionaria, la ley que limitaba el trabajo en las fábricas a doce horas por día! Proclamaban como un principio revolucionario el derecho al trabajo. ¡Vergüenza para el proletariado francés! Solamente esclavos podían 
la experiencia del encierro, es el problema de la imposibilidad del hombre para hacerse cargo de lo que le ocurre, de responder por lo que acontece, de modificar el ser. Lo que mortifica a Levinas es que el Ser acontezca "sin respuesta" (84) y, por ello, sin actor a quien responsabilizar. De este modo afirma en $D e$ la evasión: "lo que cuenta en toda esta experiencia del ser [...] es [...] la inmovilidad misma de nuestra presencia" $(\S 1,79)$. Levinas le llama a esta inmovilidad el "mal de ser" (De la existencia, 18), pero este "mal fundamental" (Algunas reflexiones, 23 ) es un "mal de época" (De la evasión, § 1,78 ), de la época moderna. Levinas reprocha a la experiencia moderna que produzca un alma de esclavo, impidiendo con ello toda posibilidad de que el hombre responda ante lo que acontece. La experiencia moderna para Levinas es la experiencia del "no-hay-nadaque-hacer" $(\S 6,104)$.

Pero es aquí donde Levinas encuentra la liga entre la experiencia del hitlerismo y las "dificultades del positivismo naturalista" ("La filosofía y el despertar", Entre nosotros, 105) moderno de las que ha surgido. El ímpetu empirista y positivista de la experiencia moderna es el generador por descuido de esa experiencia del "no hay nada que hacer". Levinas afirma en el texto "La filosofía y el despertar" que "el primer movimiento del alma ingenua" es la aceptación sin respuesta de lo que percibe: "¡Como si la evidencia del mundo en tanto que estado en el que se apoya la razón dejase estupefacta o petrificada a la vida razonable que vive esa evidencia! ${ }^{11}$ Como si la mirada in-

ser capaces de semejante bajeza. Veinte años de civilización capitalista necesitaría un griego de los tiempos antiguos para concebir tanta degradación. Si los dolores de los trabajos forzados y las torturas del hambre han caído sobre el proletariado en mayor cantidad que las langostas de la Biblia, es porque él las ha llamado". Aquí, aquello que Filón no podía concebir es lo que Lafargue defiende que los individuos "llaman". La afirmación de Levinas hereda y determina lo que hay en esa llamada.

${ }^{11}$ Habría que confrontar este acercamiento de Levinas al problema de un concepto y ejercicio de la experiencia que requiere una evidencia, una referencia, un objeto, una cosa o un hecho, con el de Heidegger en los textos escritos entre 1936 y 1938 reunidos con el nombre de Aportes a la filosofía. En ellos, en la parte 77 
genua [...] se encontrase cegada [...] o se 'aburguesase"” (104). Para Levinas este modelo empirizante de la experiencia moderna genera una "conciencia de objeto que pone nuestro ser bajo la tutela de lo que está fuera de nosotros"12 (Levinas, De la evasión, § 3, 91). Así, el sujeto de conocimiento moderno se confunde para Levinas con una "conciencia sumida a su destino" ("La filosofía", 107). Y es que esta conciencia solo puede experimentar la "impotencia ante su propia realidad. [...] impotencia ante el hecho consumado". Y añade, haciendo eco con Nietzsche: "El conocimiento es precisamente lo que queda por hacer cuando todo está consumado" (Levinas, De la evasión, $\S \S 6$ y 8, 106-114). De este modo, la experiencia moderna se convierte en la "lengua de la percepción que expresa [...] el encadenamiento de los acontecimientos" (Levinas, "La filosofía", 102), y que produce el "adormecimiento del espíritu" (76).

La experiencia moderna permite y solapa el hechizo del hombre frente a lo que le ocurre. En la experiencia al modo moderno, el hombre va hacia fuera para perderse en las cosas, para encontrarse encerrado en su ser y presente. La experiencia moderna es la del "espíritu burgués” (Levinas, De la evasión, § 1, 76),

llamada “expiriri —experiencia —experimentum - 'experimento' — $\varepsilon \mu \pi \varepsilon \imath \rho \iota \alpha-$ experiencia-intento", Heidegger afirma que el ejercicio de la experiencia que se articula con nuestra época, en la que no podemos experienciar el acontecimiento de la verdad, es la que se ejerce como una "ingenua descripción inmediata" (Aportes a la filosofía, 142) que debe "describir y asumir y constatar" (142) "el subsistir de una referencia" (141). Tal lectura de la experiencia en la época del maquinismo, de la indigencia y de la vivencia (Erlebnis), depende de la referencia al Aristóteles que afirma que es el tacto el sentido principal; $c f r$. Aristóteles, Acerca del alma. Antes de ambos, Nietzsche había atacado a los individuos modernos por cierto "empirismo burdo" al tratar sus pasiones corporales y el lenguaje. Del ejercicio de la experiencia estos individuos modernos decía que en "los sentidos es de donde procede toda credibilidad, toda buena conciencia, toda evidencia de la verdad" (Nietzsche, Más allá, § 134).

${ }^{12}$ Es esto lo que reprochará a Husserl: "Como sucede en Husserl cuando en la intencionalidad, la conciencia humana sale de sí misma, pero continúa adecuándose al cogitatum al que se iguala y que la satisface" (Levinas, "Determinación filosófica", 211). 
la del "psiquismo de la satisfacción" (Levinas, "Hermenéutica", Entre nosotros, 93) que se regodea en "el encadenamiento más radical, más irremisible, el hecho de que el yo es uno mismo" (Levinas, De la evasión, § 1,83). Levinas es enfático: la experiencia del sujeto de conocimiento moderno es la del hombre pasmado frente al sufrimiento inútil, frente a los genocidios y al hambre. El hombre encerrado en $e l$ ser es un hombre encerrado en $s u$ ser. Y el hombre pasmado ante el sufrimiento inútil es un hombre atrapado en su sufrimiento inútil. Es la experiencia del hombre irresponsable, del impedido para responder por lo que le ocurre y le ocurre a los otros. Por ello, Levinas trata de inventar "otro funcionamiento del psiquismo" ("Hermenéutica", Entre nosotros, 92) donde una experiencia ética, experiencia de la responsabilidad frente a lo que ocurre, devenga posible. El concepto de evasión, en la que "sólo aspiramos a salir"13 (Levinas, De la evasión, § 1, 82), será el primer intento de formular esta experiencia ética heterónoma. En el texto Dios, la muerte y el tiempo reaparece el problema: “¿Cómo salir del cerco del hechizo del ser?”, pregunta Levinas; pero ahora su respuesta será categórica: "Sólo [mediante] un

${ }^{13}$ Este concepto del salir o de la salida del ser que Levinas pone a funcionar es una figura que se puede encontrar en la tradición griega en la figura de Prometeo. Esquilo en Prometeo encadenado caracteriza a Prometeo como el dios que siempre encuentra argucias para salir de todas las “desdichas que ocurriéndole están”. Escribe después: "Sin razón, Prometeo te llamaron los dioses: hoy es cuando de toda tu astucia necesitas para buscar argucias que de estos artefactos pudieren liberarte" ("Prometeo encadenado", 84-87) La figura del encadenamiento - como ocurrencia de des-gracias allí se acerca al concepto de encierro en el ser de Levinas. El otro héroe de Esquilo, Palamedes, es la misma figura de Prometeo. Figura de la $\mu \varepsilon \tau 15$ (astucia), Palamedes es hábil en todos los juegos manuales y de azar. Sus "invenciones no nacen ni de la necesidad ni de la escasez [...]. Su inventiva, su fecundidad heurística, llegan a su plenitud en las situaciones difíciles, en los estados de crisis, cuando surge la aporía" (Detienne, La escritura de Orfeo, 45). Inteligencia que encuentra siempre el "recurso adecuado" en situaciones aporéticas. Por otro lado, la palabra Prometeo tiene la misma raíz que prudencia, pues etimológicamente viene de provideo, que significa tanto ver de antemano o de lejos, como cuidar de, atender, presentir, prever o tomar precauciones y las medidas necesarias para lo malo que acontece en lo que ocurre. Prometeo es el dios salidor, el inventor. 
movimiento que va hacia el otro hombre y que es fundamentalmente responsabilidad" (Dios, la muerte, 201). Es el encuentro con el otro hombre, la experiencia de salir para y hacia el otro, lo que permitirá la respuesta humana ante lo que acontece. Pero respuesta como responsabilidad respecto de otro. ${ }^{14}$ Una libertad heterónoma, experiencia inventiva.

Levinas echa a andar un "psiquismo de la inquietud y de la alerta" (Levinas, "Filosofía y positividad" apud Chalier, La huella, 14), "psiquismo de la responsabilidad respecto de otro" (Levinas, "La filosofía y el despertar", Entre nosotros, 111) que exige pensar un "traumatismo del otro" o Erlebnis heterónoma ${ }^{15}$ como "acontecimiento mismo de la trascendencia como

${ }^{14}$ En Ética e infinito, Levinas escribe: "la relación auténtica con el otro [...], la respuesta o la responsabilidad es esa relación auténtica. [...] el rostro del otro está desprotegido; es el pobre por el que yo puedo todo y a quien todo debo. [...] soy aquél que se las apaña para hallar los recursos que responda a la llamada. [...] mi sumisión y mi riqueza" (82-83).

${ }^{15}$ Levinas utiliza la palabra alemana Erlebnis en lugar de Erfahrung con toda premeditación. Uno de los primeros que se dio cuenta de lo que implicaba la modificación de una experiencia por otra en la modernidad fue Nietzsche. Así, escribe en La genealogía de la moral: "Nosotros los que conocemos somos desconocidos para nosotros, nosotros mismos somos desconocidos para nosotros mismos: esto tiene un buen fundamento. No nos hemos buscado nunca, - ¿ ¿cómo iba a suceder que un día nos encontrásemos? Con razón se ha dicho: 'Donde está vuestro tesoro, allí está vuestro corazón'; nuestro tesoro está allí donde se asientan las colmenas de nuestro conocimiento. Estamos siempre en camino hacia ellas cual animales alados de nacimiento y recolectores de miel del espíritu, nos preocupamos de corazón propiamente de una sola cosa — de 'llevar a casa' algo. En lo que se refiere, por lo demás, a la vida, a las denominadas 'vivencias'- ¿quién de nosotros tiene siquiera suficiente seriedad para ellas? ¿O suficiente tiempo?” (21).

Por su parte, Martin Heidegger renegó siempre de este concepto. Para este pensador la Erlebnis tiene sus fundamentos en la época de la imagen del mundo, cuando el sujeto metafísico deviene el fundamento de lo que hay. La "experiencia vivida" refiere al "modo y manera como el hombre es hombre" en la modernidad: como sujeto. La Erlebnis no accede al Ereignis, cfr. Ferraris, "Ereignis". Heidegger trataba de elaborar otro concepto. Así por ejemplo utiliza en "La sentencia de Anaximandro", el término Erfahrnis (algo así como experienciación) para distinguirlo de la Erlebnis y de la Erfahrung (170-171). En oposición a esto Walter Benjamin trató de determinar la vivencia del "hombre despojado de su experiencia [Erfahrung], un moderno" ("Sobre algunos temas en Baudelaire", Sobre el programa de la filosofía, 112). Benjamin trata de diagnosticar una "sustitución" histórica de la Erfahrung 
vida [...] ofreciéndose a modo de experiencia" (111; y "Vitalidad de la vida", 108). Y es que lo que está en juego en el pensamiento de Levinas es la afirmación de que somos responsables frente a los otros por lo que acontece, de que lo que acontece trae las marcas de los otros hombres, de que con la fragilidad del otro hombre arriba también el azar.

\section{REFERENCIAS}

ARISTóteles, Acerca del alma, trad. Tomás Calvo Martínez, Madrid, Gredos, 1988.

Benjamin, Walter, Sobre el programa de la filosofía futura y otros ensayos, trad. Roberto J. Vernengo, México, Origen-Planeta, 1986.

Benjamin, Walter, "Experiencia y pobreza", en Discursos interrumpidos, trad. Jesús Aguirre, Barcelona, Planeta-Agostini, 1994, 167-173.

Chalier, Catherine, La huella de infinito. Emmanuel Levinas y la fuente hebrea, trad. María Pons Irazazábal, Barcelona, Herder, 2004.

Deleuze, Gilles, "L'acte de création". Conferencia dictada el 17 de mayo de 1987 en la fundación Femis, <://www.webdeleuze. $\mathrm{com} / \mathrm{php} /$ texte.php?cle $=134 \&$ groupe $=$ Conf\%E9rences\&langu $\mathrm{e}=1>$ [fecha de consulta: 17 de abril, 2010].

Deleuze, Gilles y Claire Parnet, Diálogos, trad. José Vázquez, Valencia, Pre-textos, 1980.

Detienne, Marcel, La escritura de Orfeo, trad. Marco Aurelio Galmarini, Barcelona, Península, 1990.

De La BoÉTIE, Étienne, Sobre la servidumbre voluntaria, trad. Ángel J. Cappelletti, Buenos Aires, Libros de la Araucaria, 2006.

por la Erlebnis, para hacer de esta última un mecanismo experimental que fuerza la invención. 
Dión de Prusa, "Sobre la esclavitud y la libertad" I, en Discursos XII- XXXV, trad. Gonzalo del Cerro Calderón, Madrid, Gredos, $1989,75-83$.

Esquilo, "Prometeo encadenado", en Tragedias completas, versión rítmica de Manuel Fernández-Galiano, Barcelona, Planeta, 2000, 279-320.

FERraris, Maurizio, "Ereignis como Erlebnis", en Luto y autobiografía. De San Agustín a Heidegger, trad. Tomás Serrano, México, Taurus, 2000, 11-21.

FILÓN de Alejandría, Todo hombre bueno es libre, trad. Francisco de P. Samaranch, Buenos Aires, Aguilar, 1977.

Franco, Daniel, "Sur faces. Positions du visage chez Lévinas et Deleuze", en Gilles Deleuze. Annales de l'institut de philosophie et de sciences morales, Pierre Verstraeten, Isabelle Stengers (eds.), Paris, J. Vrin, 1998, 45-62.

Heidegger, Martin, Conceptos fundamentales. Curso del semestre de verano, Friburgo 1941, trad. Manuel E. Vázquez García, Madrid, Alianza Universidad, 1944.

Heidegger, Martin, "La sentencia de Anaximandro", en Conceptos fundamentales. Curso del semestre de verano, Friburgo 1941, trad. Manuel E. Vázquez García, Madrid, Alianza Universidad, 1944, 139-172.

HeIDEgGer, Martin, “Tiempo y ser”, ECORevista de la cultura de occidente, XXII, núm. 130, febrero, 1971, 345-376.

HeIDEGGer, Martin, "La pregunta por la técnica", Espacios, 3, 1982, 54-68.

HeIDEgGer, Martin, "Sólo un dios puede salvarnos todavía", Revista de filosofía (Universidad Iberoamericana), 66, septiembrediciembre, 1989, 4-15.

Heidegger, Martin, Aportes a la filosofía. Acerca del evento, trad. Dina V. Picotti, Buenos Aires, Biblos, 2003.

Lafargue, Paul, El derecho a la pereza. (Refutación del derecho al trabajo de 1848), <http://www.scribd.com/doc/12598676/Paul- 
Lafargue-El-Derecho-a-La-Pereza> [fecha de consulta: 21 de abril de 2010].

Levinas, Emmanuel, Ética e infinito, trad. Jesús María Ayuso Díez, Madrid, La balsa de la Medusa, 1991.

Levinas, Emmanuel, "Preguntas y respuestas", en De Dios que viene a la Idea, trad. Graciano González R. Arnaiz y Jesús María Ayuso Díez, Madrid, Caparrós, 1995, 138-168.

Levinas, Emmanuel, Dios, la muerte y el tiempo, trad. María Luisa Rodriguez Tapia, Madrid, Cátedra, 1998.

Levinas, Emmanuel, La huella del otro, trad. Esther Cohen, Silvana Rabinovich y Manrico Montero, México, Taurus, 1998.

Levinas, Emmanuel, De la evasión, trad. Isidro Herrera, Madrid, Arena libros, 1999.

Levinas, Emmanuel, De la existencia al existente, trad. Patricio Peñalver, Madrid, Arena libros, 2000.

Levinas, Emmanuel, Entre nosotros. Ensayos para pensar en otro, trad. José Luis Pardo, Valencia, Pre-textos, 2001.

Levinas, Emmanuel, Algunas reflexiones sobre la filosofía del hitlerismo, trad. Ricardo Ibarlucía y Beatriz Horrac, Buenos Aires, Fondo de Cultura Económica, 2002.

MarX, Karl, Manuscritos de economía y filosofía, trad. Francisco Rubio Llorente, Madrid, Alianza, 1984.

Nietzsche, Friedrich, II Intempestiva. Sobre la utilidad y el perjuicio de la historia para la vida, trad. Germán Cano, Madrid, Biblioteca nueva, 1999.

NieTzSChe, Friedrich, Más allá del bien y del mal, trad. Andrés Sánchez Pascual, Barcelona, Folio, 2002.

Nietzsche, Friedrich, La genealogía de la moral, trad. Andrés Sánchez Pascual, Madrid, Alianza, 2002.

NieTzsche, Friedrich, I Intempestiva. David Strauss, el confesor y el escritor, trad. Andrés Sánchez Pascual, México, Alianza, 2006.

VIDAL-NAQUET, Pierre, "Reflexiones sobre la historiografía griega de la esclavitud", en Formas de pensamiento y formas de sociedad 
en el mundo griego: el cazador negro, trad. Marco Aurelio Galmarini, Barcelona, Península, 1983, 200-224.

Zourabichvili, François, "Événement", en Le vocabulaire de Gilles Deleuze, Paris, Ellipses, 2003. 